\title{
Comprehensive evaluation of pharmacological properties of Olea europaea L. for Cosmeceuticals prospects
}

\author{
Afifa Qidwai ${ }^{1}$, Manisha Pandey ${ }^{1}$, Rajesh Kumar ${ }^{1}$ and Anupam Dikshit ${ }^{1,2^{*}}$
}

\begin{abstract}
Background: Propionibacterium acnes (anaerobic bacteria) and Staphylococcus epidermidis (aerobic bacteria) have been acknowledged as key comedone forming pathological factor, eliciting an inflammation in acne. The present study was conducted to evaluate antibacterial and antioxidant activities of Olea europaea leaves extracts (OLE) of different solvents (methanol, ethanol, deionized water, and acetone) against etiologic pathogens of acne vulgaris.

Methods: The antibacterial testing against the selected pathogen viz., P. acnes and S. epidermidis were evaluated using broth micro dilution method recommended by CLSI, in duplicate. Correspondingly the total phenolic content and flavonoid content along with radicals scavenging activity by DPPH assay were also evaluated. The data of antibacterial assay demonstrated that these plant extracts differ quantitatively in their activity against the tested pathogens.

Results: The results (mg/ml) exhibited that Olea europaea leaves extracts (MIC:2.263/IC $50: 1.626$, MIC:0.933/IC 50:0.636, MIC: 1.054/IC $50: 1.040$, MIC:2.534/IC $50: 2.500$ of aqueous, methanol, ethanol, acetone extracts respectively) are more effective against growth of P.acnes as compared to S. epidermidis (MIC: Range (Not active at particular concentration), IC $C_{50}$ : Range, MIC:1.031, IC 50 : 0.670, MIC:1.502, IC $50: 1.234$, MIC: Range, IC $50: 1.890$ mg/ml aqueous, methanol, ethanol, acetone extracts respectively). The readings were statically analyzed and also compared with standard drug tetracycline.

Conclusions: The current findings suggested Olea europaea $\mathrm{L}$. as a promising source of potential antioxidants and antibacterial activity against $P$.acnes and S. epidermidis that may be an efficient therapeutic agent in the pathogenesis of Acne vulgaris and proves a potential source of Cosmeceuticals.
\end{abstract}

Keywords: Propionibacterium acnes, Staphylococcus epidermidis, CLSI, Antibacterial activities MIC, DPPH

\section{Background}

Natural drug resources with their varied biological and pharmacological properties (due to the presence of phenolic acids, flavonoids, tannins, vitamins and terpenoids) represent a treasure for researchers, to combat problem concerning treatment of health disorders or dermal infections. In the last few years, with the increasing doses of conventional drugs, multidrug resistance of pathogens develops. To overcome these persistent dilemmas of conventional treatments an increasing interest in herbal therapy has emerged. The herbal formulations are a viable option that could be useful

\footnotetext{
* Correspondence: anupambplau@rediffmail.com

${ }^{1}$ Department of Botany, University of Allahabad, Allahabad 211002, Uttar Pradesh, India

${ }^{2}$ Biological Product Laboratory, Department of Botany, University of Allahabad, Allahabad 211002, Uttar Pradesh, India
}

in reducing the side effects associated with synthetic antibiotic treatment. Emphasis has been mainly on the antibacterial, anti-inflammatory and antioxidant properties of herbal extract [1].

Olea europaea L. leaves are a sort of waste product, this waste product is not profitable; olive leaves are often used as animal feed or simply burned with excess branches gathered [2]. The concern in olive leaves grew in the last few years due to its high pharmacologicalproperties, presence of phenolic compound flavonoids, tannins, vitamins $\mathrm{C}$ and terpenoids and high concentration of phenolic compounds [3]. O. europaea is the most abundant phenolic compound (up to $14 \%$ of the dry weight) with numerous health benefits attributed to it [4]. It has been found to have potent antioxidant and radical scavengers with anti-tumor and anti-inflammatory, 
antimicrobial properties and anti-atherogenic, hypoglycemic, hepatic, cardiac and neuro-protective effects $[5,6]$. Oleuropein has a protective effect in counteracting low-density lipoprotein (LDL) oxidation, validated through the estimation of the decreased formation of thiobarbituric acidreactive substances (TBARS are naturally present in organic specimens, include lipid hydroperoxides and aldehydes which increase in concentration as a response to oxidative stress) [7] and malondialdehyde (MDA, compound that results from the decomposition of polyunsaturated fatty acid lipid peroxides) and 4-hydroxynonenal (4-HNE) as lipid peroxides by-products [8]. Its anti-tumour activity has shown to inhibit proliferation and migration of a number of advanced grade human tumors cell lines in a dose dependent manner [9-11]. Its anti-inflammatory activity is also remarkable, demonstrated by decreasingthe production of monocytic inflammatory mediators, decreasing in the production of IL-1 $\beta$ in human whole blood cultures stimulated with monocytes-triggered by LPS [12]. Interestingly, olive oil phenolic compounds reduce the circulating concentrations of IL-6, a pro-inflammatory agent that stimulates inflammation in several pathologies. Acne vulgaris is a chronic inflammatory disorder of pilosebaceous unit that affects more than $85 \%$ of adolescents and young adults [13]. The increase sebum production, hypercornification of the pilosebaceous follicle, an abnormality of the microbial flora $(P$. acnes and S. epidermidis), and the production of inflammation are the main triggering cause of Acne vulgaris [14].

The present study intends to evaluate the antimicrobial properties of different solvent extracts of Olea europaea L. leaves (olive leaf) against most common but ticklish anaerobic bacteria of human dermal pathogen i.e. Propionibacterium acnes and aerobic bacteria Staphylococcus epidermidis, causative agent of acne vulgaris.

\section{Methods}

Olive leaves were received as a gift from Riyadh, Saudi Arabia. All the chemicals and reagents used were of analytical grade, and were either purchased from Himedia.

\section{Preparation of extracts}

Dried leaves of $O$. europaea was finely chopped and soaked overnight in $50 \%$ of different solvent i.e. methanol, ethanol, deionized water, acetone in 1:10 $(10 \mathrm{~g} / 100 \mathrm{ml})$ (Fig. 1). Subsequently, the extracts were filtered with Whatman filter paper no.1. The filtrates were subjected to evaporation under vacuum and moderate temperature in rotavapour (Advance rotatory evaporator).

\section{The test organisms}

The test organisms Propionibacterium acnes (MTCC 1951) and Staphylococcus epidermidis (MTCC 435) were procured from Microbial Type Culture Collection, Chandigarh, India and the media were procured from Hi-Media. The culture of $P$. acnes (anaerobic bacteria) was maintained on Anaerobic Blood Agar Medium supplemented with freshsheep blood. The proper anaerobic environment was provided to the bacterial culture by the Anaxomate advance instrument after which the culture was incubated for $48 \mathrm{~h}$ at $37{ }^{\circ} \mathrm{C}$ in $\mathrm{CO}_{2}$ incubator to provide optimum temperature for bacteria growth (Fig. 1). The culture of aerobic bacteria was maintained on Nutrient Agar and incubated in BOD incubator for their appropriate growth (Fig. 1).

\section{Phytochemical analysis}

All four solvents were prepared separately for extracting phenolics from leaves: methanol, ethanol, acetone and deionized water $\left(\mathrm{ddH}_{2} \mathrm{O}\right)$. Leaves $(1 \mathrm{~g})$ were ground with a mortar and pestle under liquid nitrogen. The ground leaves were supplemented to a centrifuge tube (eppendrof) containing $10 \mathrm{~mL}$ of solvent. The mixture was allowed to

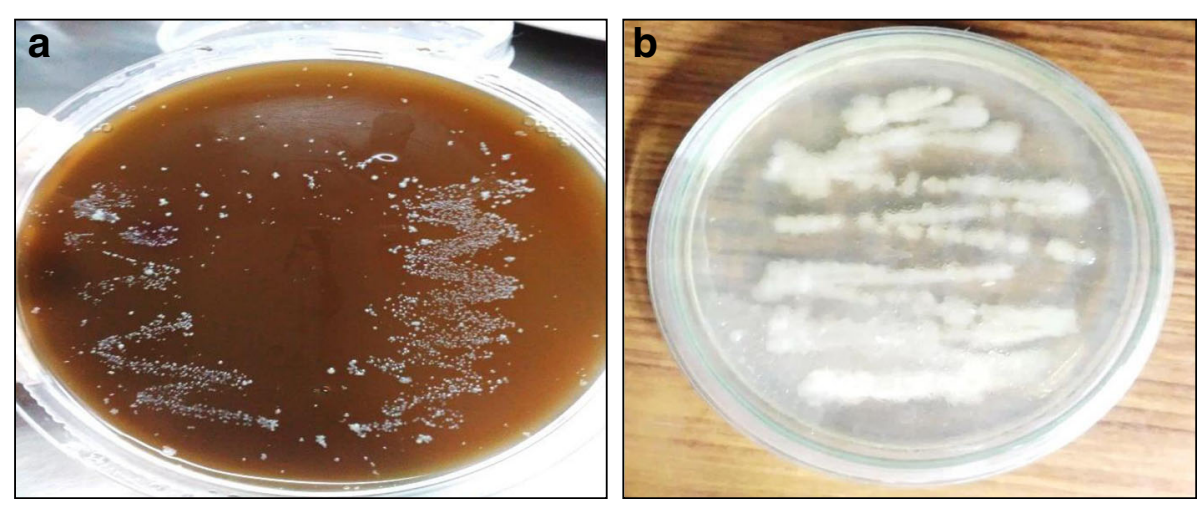

Fig. 1 The pictorial presentation of test pathogen a Culture of $P$. acne, an anaerobic bacteria, growth maintained on anaerobioc blood agar supplemented with fresh sheep blood. $\mathbf{b}$ culture of S. epidermidis an aerobic bacteria, growth maintained on Muller Hinton agar 
stand in the dark for overnight. The extract was centrifuged $5000 \mathrm{rpm}$ for $10 \mathrm{~min}$, at room temperature, and the supernatants were then filtered using a filter paper (Whatman No. 1). The extracts were subjected to rotary evaporator to make thick slurryunder vacuum at operating temperature below $45{ }^{\circ} \mathrm{C}$. Thereafter, the thick slurry was kept at $-20{ }^{\circ} \mathrm{C}$ for further usage.

1. Phenolic content: $20 \mu \mathrm{l}$ of each extract solution and standard (tannic acid) were mixed with $1 \mathrm{ml}$ of ddH2O and $100 \mu \mathrm{l}$ of Folin-Ciocalteu reagent, followed by the addition of $300 \mu \mathrm{l}$ of $20 \% \mathrm{Na}_{2} \mathrm{CO} 3$ solution after 1 minutethe resulted mixture now incubated in shaker incubator (temp $40{ }^{\circ} \mathrm{C}, 30 \mathrm{~min}$ ). The phenolic content was determined as milligram tannic acid equivalents (TAE)/g of dry weight powder (DW) [15].

2. Flavonoidscontent: $4 \mathrm{ml}$ of $\mathrm{dd}_{2} \mathrm{O}$ was mixed with $1 \mathrm{ml}$ of each olive extract. Subsequently, 5\% sodium nitrite solution $(0.3 \mathrm{~mL})$ and $10 \%$ aluminum chloride solution $(0.3 \mathrm{~mL})$ was added and incubated at room temp for 5-10 min. Then $2 \mathrm{~mL}$ of $1 \mathrm{M}$ $\mathrm{NaOH}$ was added to the mixture, the volume makes upto $10 \mathrm{ml}$ with $\mathrm{ddH}_{2} \mathrm{O}$ and subjected to vortex thoroughly. The pink colour developed and show absorbance at $510 \mathrm{~nm}$. Total flavonoids content was determined as $\mathrm{mg}$ catechin equivalents per $\mathrm{g}$ of dry weight powder (mg CE g-1 DW) [16].

3. DPPH: it is a method to measure the antioxidant/ free radical scavenging activity of extracts. The antioxidant activity/radical scavenging of leaf extracts were evaluated using 1, 1-Diphenyl-2-Picrylhydrazyl. For this purpose $0.1 \mathrm{mM}$ solution of DPPH in methanol was prepared. $30 \mu \mathrm{L}$ of extracts in different concentration $(10,50,100,500$, and $1000 \mu \mathrm{g} / \mathrm{mL}$ ) were mixed with DPPH solution and thoroughly vortex and incubated for $30 \mathrm{~min}$ at $25^{\circ} \mathrm{C}$, decrease in absorbance was measured at $\mathrm{A}=517 \mathrm{~nm}$ against blank. The standard (butylhydroxyl toluene) was used as synthetic antioxidant positive control. The scavenging ability of the plant on DPPH was calculated using the equation:

$$
\text { DPPH scavenging activity }(\%)=\frac{\text { Abs control }- \text { Abs sample }}{\text { Abs control }} \times 100
$$

Where Abs control is the absorbance of DPPH + methanol; Abs sample is the absorbance of DPPH radical + sample extract or standard [17].

\section{Antibacterial assay-}

The susceptibility of the $P$. acnes and $S$. epidermidis was assayed against Oleo europaeaL. leaf solvents extracts using the broth micro dilution method recommended by the Clinical and Laboratory Standards Institute (CLSI) [18]. Freshly prepared Muller Hinton Broth (MHB) medium was used as a base medium for the assay. Stock solutions of all the extracts and standard (Tetracycline) were prepared $(50 \mathrm{mg} / \mathrm{ml})$ in Dimethyl Sulfoxide (DMSO) and homogenized by using vortex for 4-5 min. The bacterial inocula suspension was prepared as per 0.5 McFarland standards. The experiment was performed according to CLSI guidelines in flat bottom sterile 96-well microtitre plates. Initial dispensing of $100 \mu \mathrm{l}$ medium (MHB) in all the wells, followed by the addition of $100 \mu \mathrm{l}, 90 \mu \mathrm{l}$ and $80 \mu \mathrm{l}$ of MHB in columns 2, 3 and 4 respectively. Further, $10 \mu \mathrm{l}$ and $20 \mu \mathrm{l}$ of drugs (each solvent extract in duplicate wells) were added to each well of columns 3 (sample control) and 4 (dilution well) respectively. Further, serial dilution was done from 4th column wells $(2.5 \mathrm{mg} / \mathrm{ml})$ to 11thcolumn wells $(0.02 \mathrm{mg} / \mathrm{ml})$ and after dilution, and content dragged from 11th well was discarded so as to maintain $100 \mu \mathrm{l}$ from 4-11 wells [19] (Fig. 2).

After the serial dilution, $100 \mu \mathrm{l}$ of bacterial inoculums was added to each well of column 4 to column 12, to make up final volume of $200 \mu$ l. Column 1 contained media and formaldehyde to serve as a negative control. Column 12 was taken as the positive control (O. D. control), which contains $100 \mu \mathrm{l}$ medium and $100 \mu \mathrm{l}$ inocula (Fig. 3). This is how, set of all extracts were maintained (in triplet). Thesecultured 96 well plate of anaerobic bacteria incubated in $\mathrm{CO}_{2}$ incubator (Galaxy $170 \mathrm{~S}$ New Brunswick, USA) for $48 \mathrm{~h}$ and aerobic bacterium 96 well plates were placed in BOD incubator for $24 \mathrm{~h}$.

\section{Determination of minimum inhibitory concentrations (MICs) and IC 50}

For extracts the MIC was determined as the lowest drug concentration showing absence of growth visually or $80 \%$ growth inhibition compared with the growth in the drug-free well. $\mathrm{IC}_{50}$ defined as the drug concentration that produces $50 \%$ of growth inhibition compared to the growth in the drug-free well. Comparative inhibition percent of bacteria inoculum in media treated with extracts were calculated by using formula [20].

$$
\% \text { Inhibition }=\frac{\text { O.D. } \text { Control }- \text { O.D. treatment }}{\text { O.D. } \text { control }} \times 100
$$

\section{Statistical analysis}

All experiments were carried out in duplicate. The data were analyzed using analysis of variance (ANOVA) and significant differences $(p<0.05)$ among means were determined by $\mathrm{R}$ commander software. 


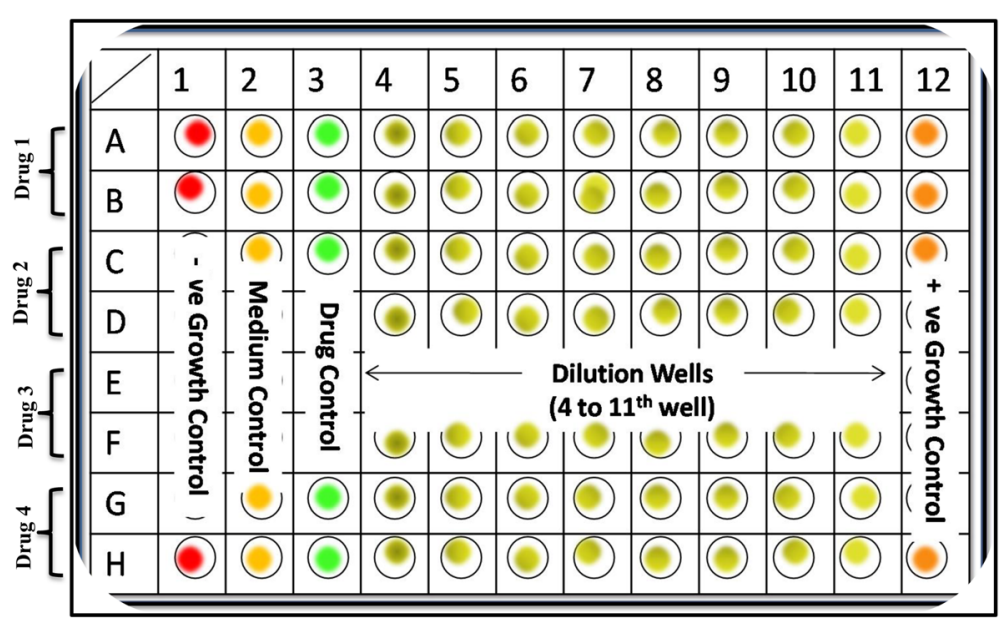

Fig. 2 Pictorial representation of CLSI recommended broth micro-dilution protocol. $a-h$ contains drugs (50mg/ml) in duplicated: $a, b$ contains Drug 1 i.e. Olea europaea ethanolic extract, $c, d$ contains Drug 2 i.e. O europaea methanolic extracts, e, $f$ Drug 3 i.e. acetone extract, $g, h$ Drug 4 contain aqueous extracts [36]

\section{Results and discussion}

In present study the preliminary qualitative and quantitative analyses of the Olea europaea L. leaves extracts (methanol, ethanol, acetone and aqueous) were executed to analyze antibacterial and antioxidant properties against $P$. acnes and $S$ epidermidis. The results of our study clearly portray significant antibacterial and antioxidant properties with reference to the MICs as well as $\mathrm{IC}_{50}(\mathrm{mg} / \mathrm{ml})$ values through 96 well microtitre plates (CLSI recommended broth micro dilution method). The leaves extracts were found to be more effective against anaerobic bacteria $P$. acnes (methanolic extracts MIC: $0.933 / \mathrm{IC}_{50}: 0.636$, ethanolic extracts MIC: $1.050 / \mathrm{IC}_{50}: 1.040$, aqueous MIC: $2.263 / \mathrm{IC}_{50}: 1.626$ and

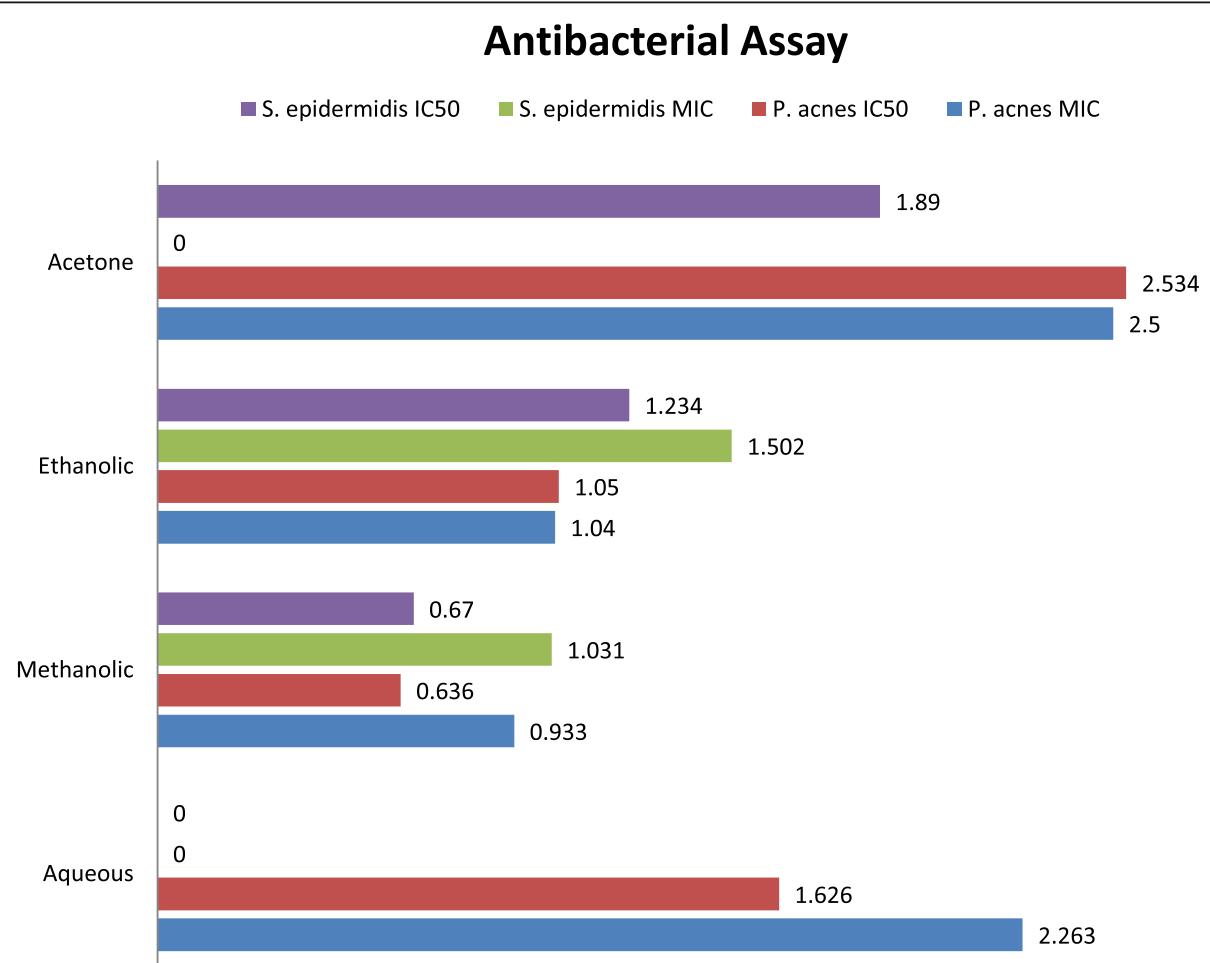

Fig. 3 Graphical presentation of activity of Olea europaea leaf extracts (acetone, ethanol, methanol and aqueous) in IC50 and MIC (mg/ml) against S. epidermidis and $P$. acnes 
Table 1 Antibacterial activity of Olea europaea leaf extracts of different solvent along with standard against P. acnes and S. epidermidis

\begin{tabular}{|c|c|c|c|c|c|c|c|c|c|c|}
\hline \multirow{4}{*}{$\begin{array}{l}\text { Pathogenic microbe } \\
\text { P. acnes }\end{array}$} & \multicolumn{10}{|c|}{$\begin{array}{l}\text { Bactericidal activity } \\
\text { (IC50 and MIC mg/ml) }\end{array}$} \\
\hline & \multicolumn{8}{|c|}{ Olea europaea } & \multicolumn{2}{|c|}{ Standard drug (Tetracycline) } \\
\hline & \multicolumn{2}{|l|}{ Aqueous } & \multicolumn{2}{|c|}{ Methanolic } & \multicolumn{2}{|c|}{ Ethanolic } & \multicolumn{2}{|c|}{ Acetone } & \multirow[b]{2}{*}{ IC50 } & \multirow[b]{2}{*}{ MIC } \\
\hline & IC50 & MIC & IC50 & MIC & IC50 & MIC & IC50 & MIC & & \\
\hline & 1.626 & 2.263 & 0.636 & 0.933 & 1.040 & 1.050 & 2.500 & 2.534 & 0.013 & 0.028 \\
\hline S. epidermidis & Range (NA) & Range (NA) & 0.670 & 1.031 & 1.234 & 1.502 & 1.890 & Range (NA) & 0.106 & 0.159 \\
\hline
\end{tabular}

NA not active at particular concentration

acetone MIC: $\left.2.534 / \mathrm{IC}_{50}: 2.500\right)$ as compared to aerobic bacteria $S$. epidermidis (methanolic extracts MIC: 1.031, $\mathrm{IC}_{50}: 0.670$, ethanolic extracts MIC: $1.502 / \mathrm{IC}_{50}: 1.234$, aqueous extracts $\mathrm{MIC}$ : Range/ $\mathrm{IC}_{50}$ : Range and acetone extracts MIC: Range/ $\left./ \mathrm{IC}_{50}: 1.890\right)$. These quantitative value were compared by standard (tetracycline) against P.acnes (MIC: 0.028, $\mathrm{IC}_{50}:$ 0.013) and S. epidermidis (MIC: 0.159, $\left.\mathrm{IC}_{50}: 0.106\right)$ (Table 1).

The Olea europaea L. leaves have a tremendous history of traditional therapeutic uses (antimicrobial and antioxidant) [21]. Olive leaves are acknowledged for the secondary metabolites such as oleacein oleuropein $[22,23]$ Flavonoids and tannins etc. were among the major phenolic contents present in plant extracts [24]. The phenolic radicals were testified to be less reactive and retain lower electron reduction potential than the oxygen radicals [25]. Owing to these properties, the phenolic compounds are reflected as excellent radical scavengers. Thus our study, correspondingly evaluates the total phenolic content and flavonoid content along with radicals scavenging activity by DPPH assay. Our data have validated that the mean phenolic content (PC) in olive leaf extracts in terms of mg dispense from 16.9 to $25.6 \mathrm{mg}$ and flavonoid content (FC) from 9.5 to 24.1 respectively (Table 2). Our results showed that methanolic, ethanolic and acetone extracts had the highest amount of phenolic content as well as flavonoid than aqueous extract [26, 27]. In general, the obtained data showed a statistical significant correlation between leaves extracts (of all the solvents) phytoconstituents analyses, i.e. total phenols and total flavonoids.

Higher the antioxidant concentration (in solvent) higher will be the percentage of DPPH scavenging activity of a compound and better will be the antioxidant activity. Further, DPPH radical scavenging activity was found to agree with total phenolics and total flavonoids outcomes. The present data revealed methanolic extracts of olive leaves exhibited appreciative higher free radical scavenging activity, followed by ethanolic $\geq$ acetone $\geq$ aqueous respectively, using DPPH. Free radical scavenging DPPH assay data dispensed from 14.7 to 92.5 (Table 2). These values were compared to the value obtained using standard $(91.8 \mu \mathrm{g} / \mathrm{ml})$. These data were also in statistical significant correlation with the data of total phenols and flavonoids. The hight free radical scavenging activity would be due to the high content of phenolic compounds in methanolic extractof $O$. europaea leaf especially oleuropein and hydroxytyrosol [28]. The reducing properties of polyphenols as hydrogen or electron-donating agents relay their potential for free-radical scavengers (antioxidants). Polyphenols holds an ideal chemical structure for free radical-scavenging activities and most of them have been shown to be strong antioxidants in vitro than vitamin E [29]. It has been demonstrated that hydroxytyrosol is empowered with a potent antioxidant activity due to the ortho diphenol function. Thus, the high antioxidant activities of oleuropein can be described by

Table 2 Phenolic content, Flavonoid content and DPPH radical scavenging activity of Olea europaea L. leaf extracts along with standard

\begin{tabular}{|c|c|c|c|c|c|c|c|}
\hline \multirow[t]{2}{*}{ Extraction solvent } & \multirow[t]{2}{*}{ Phenolic content } & \multirow[t]{2}{*}{ Total Flavonoid } & \multicolumn{5}{|c|}{$\begin{array}{l}\text { DPPH radical scavenging activity } \\
(\mu \mathrm{g} / \mathrm{ml})\end{array}$} \\
\hline & & & 10 & 50 & 100 & 500 & 1000 \\
\hline Methanolic extracts & 25.6 & 24.1 & 14.7 & 23.5 & 66.1 & 75.2 & 92.5 \\
\hline Ethanolic extracts & 24.0 & 19.5 & 14.1 & 22.9 & 64.6 & 70.2 & 86.8 \\
\hline Acetone extracts & 24.8 & 17.3 & 11.9 & 17.6 & 45.2 & 60.5 & 80.8 \\
\hline Aqueous extracts & 16.9 & 9.5 & 10.5 & 11.6 & 24.3 & 35.2 & 70.5 \\
\hline Standard & & & & & & & 91.2 \\
\hline
\end{tabular}


the presence of hydroxytyrosol unit in its structure [30, 31].

Regarding antimicrobial properties, OLE exhibits high antibacterial activity against anaerobic and aerobic bacteria causing acne vulgaris, this activity isalso in correlation with the data of above discussed results. The presence of phenolic content confers $O$. europaea L. natural resistance to microbe (Gram negative, Gram positive) outbreak [32]. Studies have demonstrated that the phenolic compounds may also stimulates antiinflammatory effects of lipoxygenase activity, leukotriene B4 production [33] and hindering biosynthesis of proinflammatory cytokines [34] or tempering inflammatory parameters [35]. Likewise COX-2, an enzyme involved in the generation of some inflammatory mediators (TNF$\alpha$ and IL- $1 \beta$ mediated enzyme) and the expression of these inflammation inducing enzymes, interleukins and tumor necrosis factors were reported to be attenuated significantly with the treatment of Olive-derived phenolic compounds [36, 37]. All these activities of OLE confer antibacterial activity against pathogens of Acne vulgaris.

\section{Conclusions}

The developing natural therapies encase naturally derived drugs from active plant extracts, essential oilsand phytomolecules. The antibacterial and antioxidant potential of the olive leaf extracts can be attributed to its high contents of phenols, flavonoids and vitamin $\mathrm{C}$ that act synergistically. Although there is an observed significant variation in chemical constituents and biological activities of olive leaf extracts treated with different solvents, the current findings support that this medicinal plant Olea europaea L. is a promising source of potential antibacterial and antioxidants that may be efficient therapeutic agent in the pathogenesis of acne vulgaris and proves potential source of Cosmeceuticals.

\section{Acknowledgement \\ The authors would like to expresstheir gratitude to Head, Department of Botany, and University of Allahabad to providing research facilities, UGC, New Delhi for financial support, Mr. Rick Z for providing anaerobic jar and Moti Lal Nehru Medical College, Allahabad for providing the anaerobic culturing facilities.}

\section{Authors' contributions}

$\mathrm{AQ}$ conducted the experiments and design conception and conduction of research. Data interpretation and analysis were done by MP participated in drafting the manuscript revised the manuscript critically for important intellectual content. RK critically reviews the manuscript. AD made the necessary corrections in the write up and gave final approval for the submission of revised version. All authors read and approved the final manuscript.

\section{Competing interests}

The authors declare that they have no competing interests.

\section{Publisher's Note}

Springer Nature remains neutral with regard to jurisdictional claims in published maps and institutional affiliations.
Received: 8 November 2016 Accepted: 24 May 2017

Published online: 04 July 2017

\section{References}

1. Kumar R, Shukla SK, Pandey A, Pandey H, Pathak A and Dikshit A: Dermatophytosis: Infection and Prevention -A Review. Int J Pharm Sci Res 2016;7(8):3218-25.

2. Tsatsanis C, Androulidaki A, Venihaki M, Margioris AN. Signalling networks regulating cyclooxygenase-2. Int J Biochem Cell Biol. 2006;38:1654-61.

3. Makari H, Haraprasad N, Patil H, Ravi k. In vitro antioxidant activity of the hexane and methanolic extracts of Cordia Wallichii and Celastrus paniculata. The Internet J. Aesthetic and Antiaging Med.. 2008; 1: 1-10

4. Ghanbari R, Anwar F, Alkharfy KM, Gilani AH, Saari N. Valuable nutrients and functional bioactives in different parts of olive (Olea europaea L.)-A review. Int J Mol Sci. 2012;13:3291-340.

5. Cicerale S, Conlan XA, Sinclair AJ, Keast RS. Chemistry and health of olive oil phenolics. Crit Rev Food Sci Nutr. 2009:49:218-36.

6. Cicerale S, Lucas L, Keast R. Biological activities of phenolic compounds present in virgin olive oil. Int J Mol Sci. 2010;11:458-79.

7. Armstrong D, Browne R. Free Rad. Diag Med. 1994;366:43-58.

8. Visioli F, Bellomo G, Montedoro G, Galli C. Low density lipoprotein oxidation is inhibited in vitro by olive oil constituents. Atherosclerosis. 1995;117:25-32.

9. Chimento A, Casaburi I, Rosano C, Avena P, De Luca A, Campana C, Martire E, Santolla MF, et al. Oleuropein and hydroxytyrosol activate gper/ gpr30dependent pathways leading to apoptosis of er-negative skbr3 breast cancer cells. Mol Nutr Food Res. 2013;58:478-9.

10. Carrera-González MP, Ramírez-Expósito MJ, Mayas MD, Martínez-Martos JM. Protective role of oleuropein and its metabolite hydroxytyrosol on cancer. Trends Food Sci Technol. 2013;31:92-9.

11. Cardeno A, Sanchez-Hidalgo M, Rosillo MA, AlarcondelaLastra C. Oleuropein, a secoiridoid derived from olive tree, inhibits the proliferation of human colorectal cancer cell through downregulation of hif-1alpha. Nutr Cancer. 2013;65:147-56.

12. Miles EA, Zoubouli P, Calder PC. Differential anti-inflammatory effects of phenolic compounds from extra virgin olive oil identified in human whole blood cultures. Nutrition. 2005:21:389-94.

13. Qidwai A, Pandey M, Shukla SK, Pandey A, Kumar R, Dikshit A. Risk factor assessment for Acne vulgaris in human and implications for public health interventions in north central India: A survey based study. 2017;10(5):404-409.

14. Qidwai A, Pandey M, Pathak S, Kumar R, Dikshit A. The emerging principles for acne biogenesis: A dermatological problem of puberty. Human Microbiome Journal. 2017;4:7-13.

15. Arabshahi S, Urooj A. Antioxidant properties of various solvent extracts of mulberry (Morusindica L.) leaves. Food Chem. 2007;102:1233-40.

16. Kim D, Jeong S, Lee C. Antioxidant capacity of phenolic phytochemicals from various cultivars of plums. Food Chem. 2003;81:321-26.

17. Shimada K, Fujikawa K, Yahara K, Nakamura T. Antioxidative properties of xanthone on the auto oxidation of soybean in cylcodextrin emulsion. J Agr Food Chem. 1992:40:945-8.

18. Methods for dilution antimicrobial susceptibility tests for bacteria that grow aerobically (5th Ed.). Approved standard, M7-A5. Pennsylvania: Wayne. NCCLS, 2003

19. Qidwai A, Pandey M, Shukla SK, Kumar R, Pandey A, Dikshit A. Antibacterial activity of mentha piperita and citrus limetta against Propionibacterium acnes (anaerobic bacteria). Int J Pharma Sci Res. 2016;7(7):2917-24.

20. Pathak A, Shukla SK, Pandey A, Mishra RK, Kumar R, Dikshit A. In vitro antibacterial activity of Ethno medicinally used lichens against three wound infecting genera of Enterobacteriaceae. Proc. Natl. Acad. Sci. India B Biol. 2015;86:1-2

21. Soni MG, Burdock GA, Christian MS, Bitler CM, Crea R. Safety assessment of aqueous olive pulp extract as an antioxidant or antimicrobial agent in foods. Food ChemToxicol. 2006;44:903-15.

22. Pereira AP, Ferreira ICFR, Marcelino F, et al. Phenolic compounds and antimicrobial activity of olive (Olea europaea L. Cv. Cobrançosa) leaves. Molecules. 2007;12:1153-62.

23. Sato $H$, Genet $\mathrm{C}$, Strehle A, et al. Anti-hyperglycemic activity of a TGR5 agonist isolated from Olea europaea. BiochemBiophys Res Commun. 2007; 362:793-8.

24. Kaur C, Kapoor HC. Anti-oxidant activity and total phenolic content of some Asian vegetables. Int. J. Food Sci. Technol., 2002;37:pp.153-161. 
25. Gillespie KM, Chae JM, Ainsworth EA. Rapid measurement of total antioxidant capacity in plants. Nat Protocols. 2007;2(4):867-70.

26. Ali MA, Nancy SR, Aboubaker MG, Said KA. Antibacterial effect of olive (Olea europaea $\mathrm{L}$.) leaves extract in raw peeled undeveined shrimp (Penaeus semisulcatus). Int J. of Veterin Sci and Med . 2014;2(1):53-56.

27. Ainsworth EA, Gillespie KM. Estimation of total phenolic content and other oxidation substrates in plant tissues using Folin-Ciocalteu reagent. Nat Protocols. 2007;2(4):875-7.

28. Khlif I, Jellali K, Michel T, Halabalaki M, Skaltsounis AL, Allouche N. Characteristics, phytochemical analysis and biological activities of extracts from Tunisian chetoui olea europaeaVariety. J Chem. 2015;2015:11.

29. Goldsmith CD, Vuong QV, Stathopoulos CE, Roach PD, Scarlett CJ. Optimization of the aqueous extraction of phenolic compounds from olive leaves. Antioxidants. 2014;3(4):700-12.

30. Allouche N, Fki I, Sayadi S. Toward a high yield recovery of antioxidants and purified hydroxytyrosol from olive mill wastewaters. J Agri Food Chem. 2004:52(2):267-73

31. Cicerale S, Lucas LJ, Keast RS. Antimicrobial, antioxidant and antiinflammatory phenolic activities in extra virgin olive oil. Curr Opin Biotechnol. 2012;23:129-35.

32. Sousa A, Ferreira IC, Barros L, Bento A, Pereira JA. Effect of solvent and extraction temperatures on the antioxidant potential of traditional stoned table olives "alcaparras". LWT-Food Sci Tech. 2008;41(4):739-45.

33. Lee OH, Lee BY, Lee J, Lee HB, Son JY, Park CS, Shetty K, Kim YC Assessment of phenolics-enriched extract and fractions of olive leaves and their antioxidant activities. Biores tech. 2009;100(23):6107-13.

34. Lihu Y, Yueming J, Datta N. HPLC analyses of flavanol and phenolic acids in the fresh young shoots of tea (Camellia sinesis) grown in Australia. Food Chem. 2004;84:253-63.

35. Manian R, Anusuya N, Siddhuraju P, Manian S. The antioxidant activity and free radical scavenging potential of two different solvent extracts of Camellia sinensis (L.) O. Kuntz, Ficusbengalensis L. and Ficusracemosa L. Food Chem. 2008:107:1000-7.

36. Pandey M, Pandey A, Kumar R, Pathak A, Dikshit A. A Comparative antimicrobial analysis of Tridaxprocumbens $L$. various extracts on waterborne bacterial pathogens. Int Cur Pharma J. 2016;5(3):22-6.

37. Goldsmith CD, Vuong QV, Sadeqzadeh E, Stathopoulos CE, Roach DE, Scarlett CJ. Phytochemical Properties and Anti-Proliferative Activity of Olea europaea L. Leaf Extracts against Pancreatic Cancer Cells. Molecules. 2015;20:12992-13004.

\section{Submit your manuscript to a SpringerOpen ${ }^{\circ}$ journal and benefit from:}

- Convenient online submission

- Rigorous peer review

- Open access: articles freely available online

- High visibility within the field

- Retaining the copyright to your article

Submit your next manuscript at $\boldsymbol{s p r i n g e r o p e n . c o m ~}$ 